\title{
A Sequential Solution with MCDM Methods at the Motor-Yacht Construction Problem
}

\author{
(i) G. Nilay Yücenur
}

Beykent University, Faculty of Engineering and Architecture, Department of Industrial Engineering, İstanbul, Turkey

\begin{abstract}
Yachting is quite popular in recent years and it is defined as an "entertainment and vacation industry in the sea." The yachting industry as parallel to the world economy is developing rapidly in financial, industrial, and physical spaces in the world and in Turkey as well. With this development, yachting provides foreign currency inflow to Turkey in the tourism sector as well as in the construction industry according to the Turkish Statistical Institute's data. Turkey is greatly known in the European yacht and boat market particularly in terms of engine manufacture and specialization, low labor cost, and quality advantages. This study is aimed to determine a suitable shipyard's city to carry out a 30-meter motor yacht. In this research study, a model was suggested for selecting the appropriate shipyard for motor-yacht construction with a proposed solution methodology. In the research methodology, 15 criteria were determined for evaluating 4 shipyards that have different properties and are located in different cities of Turkey. In the first phase of the solution, SWARA was used to obtain the importance weights of the criteria. In the second phase of the solution, alternatives were evaluated with COPRAS according to the calculated importance weights. The proposed model and solution methodology were conducted through an explanatory sample.
\end{abstract}

Keywords

MCDM, SWARA, COPRAS, Yacht and boat industry, Shipyard location

\section{Introduction}

In recent years, technological developments in the world and intense competition have greatly influenced the development of the shipbuilding industry. As a result, the structure and capacity of ships have increased. The maritime sector and boat production in the world is among the sectors that governments have prioritized in the development of the industry in many countries, as it produces high-quality employment and added value in the region as well as almost no harm to the environment.

The yachting market, which developed parallel to the maritime sector, has been one of the most popular business areas in recent years due to the characteristics of target customers and market trends. The demand for luxury yachts also affects many economic sectors such as textiles, fashion, jewelry, and furniture. The consumers' desires and demands for new products ensure these supporting sectors to develop themselves as well. Companies with the highest production quality and brand awareness in these sectors create new markets for them as well as strengthen their position and brand image in the richest consumer group in the world. With the developing yachting market, the number of produced yachts increased from 108 to 180 between 2000-2010 in Turkey. Besides this, the share of yacht production in exports of ships and yachts on the basis of goods groups was $11.7 \%$, while the share of the ship subindustry was $4.8 \%$ in $2015-2016$. The growing rate of the yacht sub-industry cannot be belittled [1,2].

Therefore, this paper aims to select the most appropriate shipyard among four alternatives, which are in different cities in Turkey for constructing a 30-meter motor yacht. In this study, a sequential methodology consisting of The Stepwise Weight Assessment Ratio Analysis (SWARA) and Complex Proportional Assessment (COPRAS) was proposed. In the literature review, there are lots of applications in many different areas about SWARA, which determines the

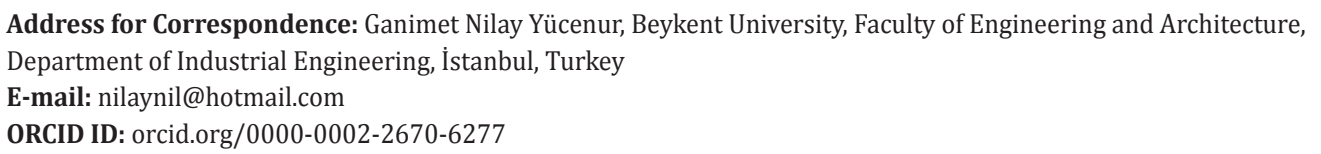

To cite this article: G.N. Yücenur, "A Sequential Solution with MCDM Methods at the Motor-Yacht Construction Problem." Journal of ETA Maritime Science, vol. 9(3), pp. 168-176, 2021. 
criteria's importance weights. This new method enables researchers to solve real-life problems. For example, with the SWARA method, Rani et al. [3] evaluated the solar panel, Mostafaeipour et al. [4] ranked locations for geothermal energy, Mardani et al. [5] assessed key challenges of digital health interventions, Chen et al. [6] modeled the landslide susceptibility, Naeini et al. [7] analyzed the development of biodiesel production, Mousavi-Nasab and Sotoudeh-Anvari [8] evaluated renewable energy resources, and Balali et al. [9] identified the passive energy consumption.

Likewise, according to the literature review, the COPRAS method, which is applied to evaluate problems according to complex criteria, has been used to solve problems in different fields. For example, with the COPRAS method, Roozbahani et al. [10] planned the water transfer interbasin, Dhiman and Deb [11] determined hybrid wind farms, Rani et al. [12] applied the method in pharmacological therapy, and Kathamore and Bachchhav [13] classified the bio-based lube oil. Mishra et al. [14] evaluated the healthcare in hazardous waste recycling, Kumari and Mishra [15] selected the green supplier, Garg and Arora [16] made a decision with possibility intuitionistic, and Singh et al. [17] designed brake friction materials.

Even though the solution with these methods is included in the studies of Zarbakhshnia et al. [18], Valipour et al. [19], Yücenur et al. [20], Ansari et al. [21], Mishra et al. [22], and Rani et al. [23] about the selection of a third-party reverse logistics provider, the allocation of risk in water and sewerage projects, selection of city for biogas facility, evaluation of solutions to sustainable remanufacturing supply chain risks, evaluation of bioenergy production process, and selection of sustainable supplier, there is no similar study on yachting and the marine industry available in the literature.

\section{Yachting and Boat Industry in Turkey}

The yacht and boat manufacturing industry has a very high added value, a high export rate, and provides employment to countries. Various service sectors serve this manufacturing industry. The integration of products like machinery, iron and steel, wood, paint-chemistry, electricity, electronics, textile, decoration, rubber, and plastic are used in shipyards. The yacht and boat industry is different from the shipbuilding industry in terms of both the content and scope and the technology it applies. While the shipbuilding industry needs large investments, long periods, and large seaside locations, the yacht and boat manufacturing industry sometimes can operate in a shorter time and in smaller places with a smaller investment. Although investments in shipyards that build luxury yachts are higher than those made in shipyards that build normal ships with a length of $30 \mathrm{~m}$, depending on the materials used, the technology used, the desired features and demands, the yacht industry is one of the sectors with the highest added value [2].

In terms of the geographical structure of Turkey, the yacht and boat industry has a huge advantage. Besides this geographical advantage, the industry has workmanship and material qualities, cost advantages, owned marinas, yacht locations, and the ability of manufacturers to meet customer demands. With these positive aspects, the sector is quite open to development. Besides these, the training of qualified naval architects with activities of shipbuilding, ship machinery, ship electricity, casting, and profession branches in education activities revised with the contributions of the naval architecture and marine sciences faculties of universities and the shipbuilding industrialists' union is the important advantages of Turkey in this sector. Although Turkey's entry into the sector was very new compared to its competitors in Europe, it has gained an important place in the sector in a short time. Considering the number of boats delivered over 30 meters, Turkey ranked fourth after Italy, the USA, and the Netherlands for 2011 [1].

The Turkish boat and yacht building industry, which has developed rapidly since the 1980s, has become one of the world's leading producers thanks to its workforce, quality manufacturing, modern technology, and superior entrepreneurship spirit.

As the sector grew rapidly in the country, parallel to this, the number of active shipyards, which was 37 in 2002, reached 79 by the end of 2015. These shipyards are concentrated in the Marmara and Western Black Sea regions, and about 23 shipyards are in the investment phase of the country. In addition, 15 new shipyard areas have been identified [2].

In Turkey, superyachts ( $24 \mathrm{~m}$ and above) construction has especially shown a steady increase since 2007 . According to data from 2010, Turkey was the third manufacturer in the world due to the quantity and length of delivered superyachts. Turkey was again third in the world with 68 projects and with a total of 3,005 meters in length in 2014. The country was again third in 2016 and maintained its place in the sequencing all over the world according to 2017's data with 3508-meter superyacht orders [2].

The sector is highly influential on the country's economy. Almost all ships built in shipyards in Turkey between 20082012 have been exported to the European Union countries and the number of exports of new ships and yachts in 2012 was 813 million dollars [24].

\section{Research Problem}

While the yacht building industry and used shipyards for yacht building have an important place for the development 
of Turkey in the maritime sector, the country also has strategic importance for the development of the yacht building industry in Europe. The geographical position, climatic conditions, and production costs provide the country with a great competitive advantage in terms of yacht building.

In this study, the selection of the appropriate shipyard for the construction of a 30-meter motor yacht in the developing yacht industry is carried out by a sequential methodology integrating SWARA/COPRAS.

Figure 1 shows the proposed research model with 15 criteria and 4 alternatives.

\subsection{Problem}

The problem of this paper is to select the most appropriate alternative shipyard for a 30-meter motor-yacht construction in Turkey.

\subsection{Research Criteria}

To determine the shipyard to be selected in the construction of the 30-meter motor yacht, 15 criteria were determined according to the literature review and sector experts' opinions. Table 1 shows the evaluation criteria's explanations.

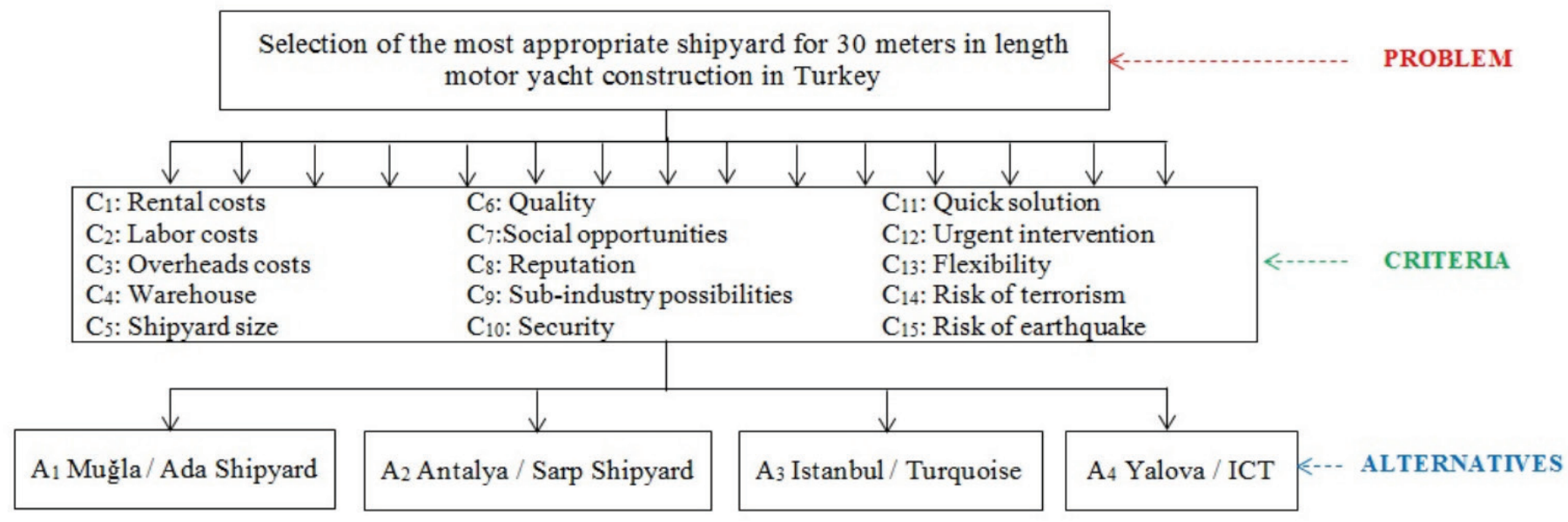

Figure 1. Proposed research model

Table 1. Evaluation criteria and their explanations

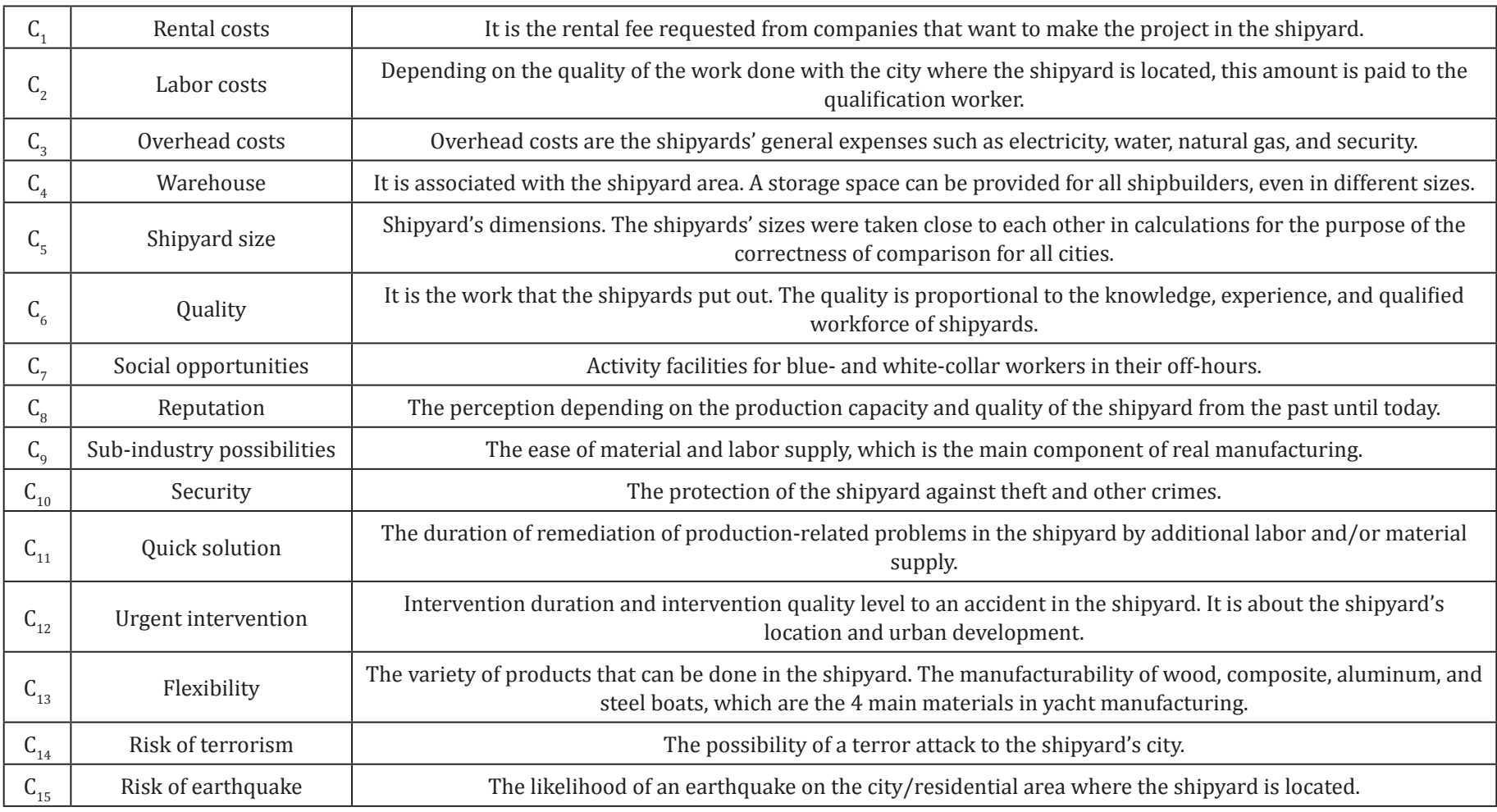




\subsection{Research Alternatives}

Four shipyards with different characteristics found in different cities where a 30-meter yacht construction can be carried out were determined as alternatives. These shipyards have been preferred because they are the most established companies in their regions, they are of different sizes, and they are located in different regions to use the distinctive features of the criteria. For this purpose, the alternative shipyards that will be considered to solve the problem are found in Muğla, Antalya, İstanbul, and Yalova.

- A Muğla/Ada Shipyard: The Ada Shipyard is located in the southwest of Turkey. It has ISO 9001:2008, OHSAS 18001:2007, and ISO 14001:2004 standards about quality, occupational health, and the environment. The shipyard is a reliable shipyard that provides a customer-focused service and attaches importance to quality and detail with years of experience in shipbuilding.

- A Antalya/Sarp Shipyard: This shipyard is located in the free zone of Antalya in the south of Turkey. The Sarp shipyard was specifically designed for the construction and refitting of luxury motors and sailing yachts. It also has ISO 9001, ISO 14001, and OHSAS 18001.

- A İstanbul/Turquoise: This shipyard was established in 1997 by two Turkish boat companies. The Turquoise Yachts, which is located in İstanbul's most crowded city in Turkey, offers quality turnkey solutions in its facilities to yacht lovers.

- $\mathbf{A}_{4}$ Yalova/ICT: Located in Yalova, the ICT Shipyard was established on a 31,000-square meter seafront land, with a total closed facility of 4,500 square meters. The location of the shipyard has an important advantage by staying out of commercial shipyard areas and being separated from sandblasting and all other negativities.

\section{A Proposed Solution Methodology with SWARA \& COPRAS}

Turkey with its long coasts, yacht tourism facilities, and wealth of culture and history, is an important international market, especially for superyachts. In this paper, a methodological framework has been established to solve the problem of shipyard selection that is suitable for yacht construction due to all these sectoral developments. A solution was proposed in which the alternatives are evaluated according to criteria established by decision makers and two MCDM methods were integrated to find the most appropriate solution to the problem. SWARA was used in the first step of the solution method for weighing of determined criteria. In the second step of the solution method, COPRAS was used to select the most suitable shipyard for the 30-meter motor-yacht construction.

The COPRAS method integrated with SWARA in the study is based on experts' opinions. This proposed integrated method has been chosen because it provides convenience, coordination, and simplicity in the data collection. The fact that complex processes are not needed to evaluate the criteria in the method and that the solution of the problem can be done in a short time are other advantages of this integrated method. Figure 2 shows the integration of this proposed integrated method.

\subsection{SWARA}

The most important issue in many MCDM problems is to determine the criteria weights. In this paper, SWARA was used for determining the criteria weights. The SWARA method, which is a new method of weight determination and which has been used frequently in recent years, has been put forward by Keršuliene et al. [25]. The method offers the opportunity to evaluate criteria weights

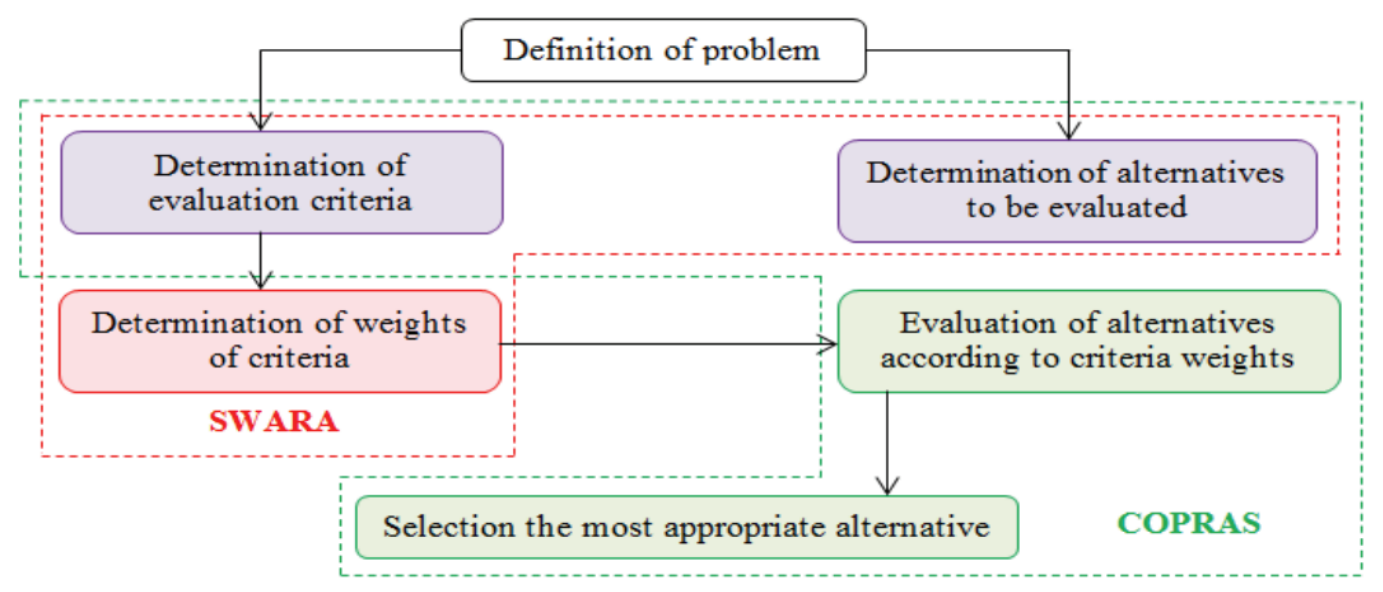

Figure 2. Decision-making process by the SWARA-COPRAS method

SWARA: The Stepwise Weight Assessment Ratio Analysis, COPRAS: Complex Proportional Assessment 
and to use the knowledge and experience of experts in calculations. Thus, experts have a chance to prioritize the criteria based on their needs and target characteristics.

Application steps of SWARA [26]:

Step 1: All criteria are sorted from the most important to the least important one by each decision maker's individual judgment. The same criteria are then sorted again due to fist ranking. $p_{j}^{k}$ are obtained $\left(0 \leq p_{j}^{k} \leq 1\right)$ in this sorting. Table 2 shows the first ordering of criteria.

Step 2: The relative average importance scores $\left(\bar{P}_{j}\right)$ for all criteria are calculated for all criteria using equation 1 . Table 2 shows the second ordering and the $\bar{P}_{j}$ of criteria.

$\bar{P}_{J}=\frac{\sum_{k=1}^{l} p_{j}^{k}}{l} ; j=1,2, \ldots, n$

Here, $l$ is the number of decision makers.

Step 3: Criteria are listed according to the $\bar{P}_{j}$ in descending order. The $s_{j}$ values (comparative importance of average value) are obtained as seen in Table 3. According to this table, the order of importance of the criteria was obtained as $\mathrm{C}_{9}>\mathrm{C}_{1}>\mathrm{C}_{3}>\mathrm{C}_{2}>\mathrm{C}_{5}>\mathrm{C}_{4}>\mathrm{C}_{6}>\mathrm{C}_{8}>\mathrm{C}_{10}>\mathrm{C}_{13}>\mathrm{C}_{12}>\mathrm{C}_{11}>\mathrm{C}_{7}>\mathrm{C}_{15}>\mathrm{C}_{14}$.

Step 4: With the binary comparison for all criteria, the coefficient value $c_{j}$ is obtained using equation $2 . c_{j}=1$ for the criterion with the greatest $s_{j}$

$c_{j}=s_{j}+1 ; j=1,2, \ldots, n$
Step 5: For all criteria, the corrected weights $s_{j}^{\prime}$ are calculated with equation $3 . s_{j}^{\prime}=1$ for the first criterion in ranking.

$$
s_{j}^{\prime}=\frac{s_{j-1}^{\prime}}{c_{j}}
$$

Step 6: For all criteria, the final importance weights $w_{j}$ are obtained with equation 4 .

$$
w_{j}=\frac{s_{j}^{\prime}}{\sum_{j=1}^{n} s_{j}^{\prime}} ; j=1,2, \ldots, n
$$

Table 3 shows $c_{j}, s_{j}^{\prime}$, and $w_{j}$ values for 15 criteria.

As seen in Table 3, $\mathrm{C}_{9}$ (with a score of 9.5\%) is the most important criterion according to the proposed model and experts' opinion. $\mathrm{C}_{1}$ (with a score of $9.1 \%$ ) and $\mathrm{C}_{3}$ (with a score of $9.0 \%$ ) follow this criterion, while the least important one is $\mathrm{C}_{14}$ (with a score of $4.1 \%$ ).

\subsection{COPRAS Method}

After the calculation of criteria weights with SWARA, COPRAS is used to evaluate the alternatives. It is not possible for a single criterion to express the entirety of objectives being watched by the users. For this reason, COPRAS was developed by the researchers [27]. COPRAS includes the phasing and ranking of alternatives based on the importance and utility of the criteria. At the same time, the method can easily be applied to complex criteria and problems involving numerous alternatives.

Table 2. First and second ordering and $\overline{P_{j}}$ of fifteen criteria

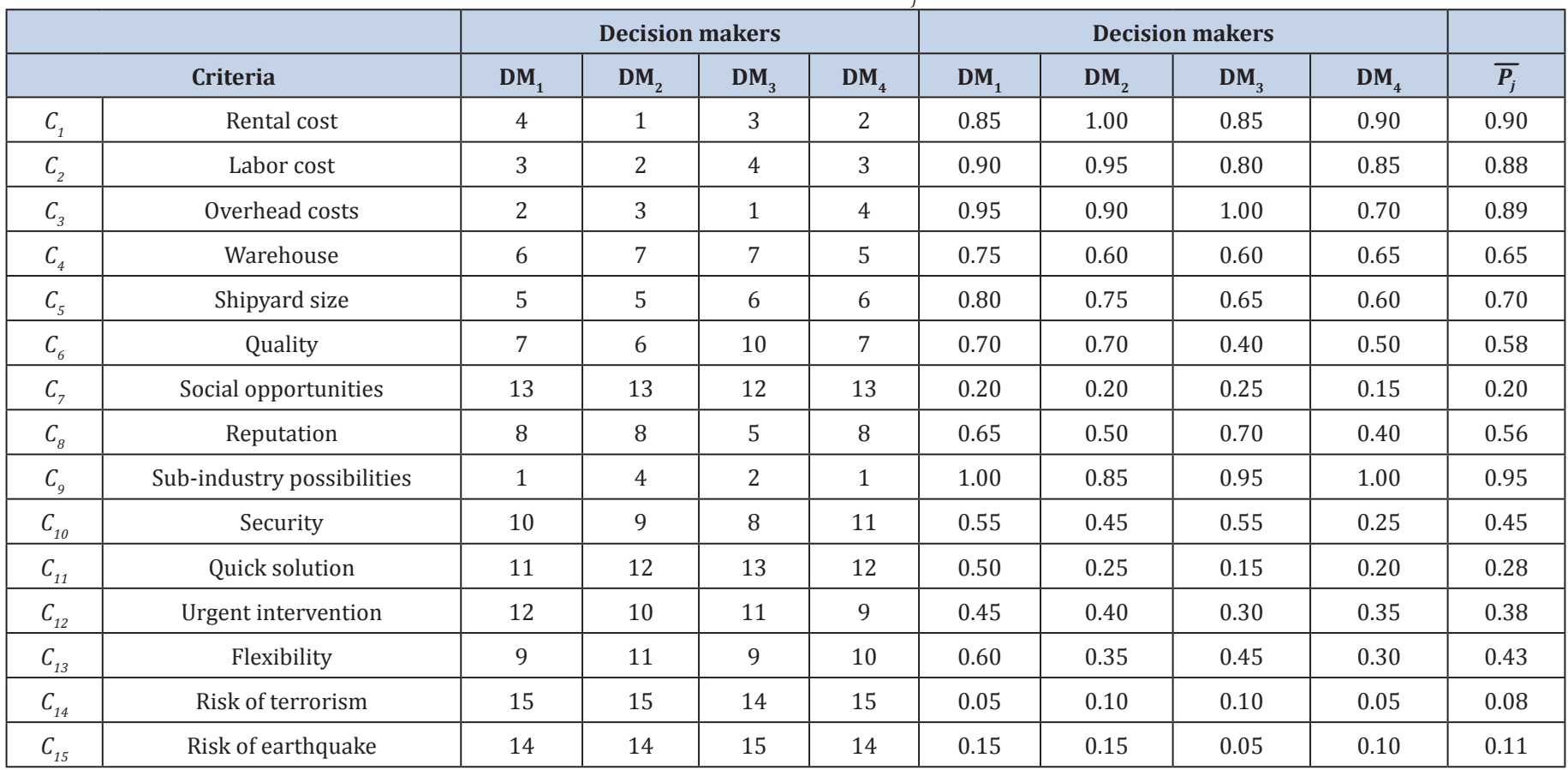




\section{Application steps of COPRAS [21,23]:}

Step 1: $m$ (number of alternatives- $i=1,2, \ldots, m$ ) and $n$ (number of evaluation criteria- $j=1,2, \ldots, n$ ) values are determined.

Step 2: With equation 5, the decision matrix is formed. Here, $C_{j}$ shows the decision criteria, $w_{j}$ shows the importance weights of criteria that were calculated by the SWARA method, $A_{i}$ shows alternative shipyards, and $x_{i j}$ shows the value of alternative $i$ according to criterion $j(i=1,2, \ldots, m$ and $j=1,2, \ldots, n$ ).

$$
\begin{aligned}
& \begin{array}{llllll}
C_{1} & C_{2} & C_{3} & C_{4} & \ldots & C_{n}
\end{array} \\
& \begin{array}{llllll}
w_{1} & w_{2} & w_{3} & w_{4} & \ldots & w_{n}
\end{array} \\
& A_{1} \quad\left[\begin{array}{lllll}
x_{11} & x_{12} & x_{13} & \ldots & x_{1 n} \\
x_{21} & x_{22} & x_{23} & \ldots & x_{2 n}
\end{array}\right. \\
& D A_{2} \quad \begin{array}{lllll}
x_{21} & x_{22} & x_{23} & \ldots & x_{2 n} \\
x_{31} & x_{32} & x_{33} & \ldots & x_{3 n}
\end{array} \\
& \begin{array}{llllll}
A_{3} & x_{31} & x_{32} & x_{33} & \ldots & x_{3 n}
\end{array} \\
& \begin{array}{c}
\vdots \\
A_{m}
\end{array}\left[\begin{array}{ccccc}
x_{m 1} & x_{m 2} & x_{m 3} & \ldots & x_{m n}
\end{array}\right]
\end{aligned}
$$

Table 4 shows the decision matrix for the subjective and objective criteria assessment of the application problem.

Table 3. $\bar{P}_{\dot{\rho}} c_{\rho} s_{j}^{\prime}$ and $w_{j}$ values

\begin{tabular}{|c|c|c|c|c|c|}
\hline \multicolumn{2}{|c|}{ Criteria } & $\overline{\boldsymbol{P}}_{\boldsymbol{j}}$ & $\boldsymbol{c}_{\boldsymbol{j}}$ & $\boldsymbol{s}_{\boldsymbol{j}}^{\prime}$ & $\boldsymbol{w}_{\boldsymbol{j}}$ \\
\hline$C_{9}$ & Sub-industry possibilities & 0.95 & 1.00 & 1.00 & 0.095 \\
\hline$C_{1}$ & Rental cost & 0.90 & 1.05 & 0.95 & 0.091 \\
\hline$C_{3}$ & Overhead costs & 0.89 & 1.01 & 0.94 & 0.090 \\
\hline$C_{2}$ & Labor cost & 0.88 & 1.01 & 0.93 & 0.089 \\
\hline$C_{5}$ & Shipyard size & 0.70 & 1.18 & 0.79 & 0.076 \\
\hline$C_{4}$ & Warehouse & 0.65 & 1.05 & 0.75 & 0.072 \\
\hline$C_{6}$ & Quality & 0.58 & 1.08 & 0.70 & 0.067 \\
\hline$C_{8}$ & Reputation & 0.56 & 1.01 & 0.69 & 0.066 \\
\hline$C_{10}$ & Security & 0.45 & 1.11 & 0.62 & 0.059 \\
\hline$C_{13}$ & Flexibility & 0.43 & 1.03 & 0.61 & 0.058 \\
\hline$C_{12}$ & Urgent intervention & 0.38 & 1.05 & 0.58 & 0.055 \\
\hline$C_{11}$ & Quick solution & 0.28 & 1.10 & 0.53 & 0.050 \\
\hline$C_{7}$ & Social opportunities & 0.20 & 1.08 & 0.49 & 0.047 \\
\hline$C_{15}$ & Risk of earthquake & 0.11 & 1.09 & 0.45 & 0.043 \\
\hline$C_{14}$ & Risk of terrorism & 0.08 & 1.04 & 0.43 & 0.041 \\
\hline
\end{tabular}

The objective information that is essential for the criteria, " $C_{1}$-Rental cost," " $C_{2}$-Labor cost," and " $C_{5}$-Shipyard size" are obtained.

Step 3: The normalization procedure of the decision matrix $D$ is performed by equation 6 and the normalized decision matrix that is seen in equation 7 is obtained.

$$
\tilde{x}_{i j}=\frac{x_{i j}}{\sum_{i=1}^{m} x_{i j}}
$$

$$
\begin{aligned}
& \begin{array}{llllll}
C_{1} & C_{2} & C_{3} & C_{4} & \ldots & C_{n} \\
W_{1} & W_{2} & W_{3} & W_{4} & &
\end{array} \\
& \begin{array}{lllllll}
w_{1} & w_{2} & w_{3} & w_{4} & \ldots & w_{n}
\end{array} \\
& \widetilde{D}=\begin{array}{c}
A_{1} \\
A_{2} \\
A_{3} \\
\vdots \\
A_{m}
\end{array}\left[\begin{array}{ccccc}
\widetilde{x}_{11} & \widetilde{x}_{12} & \widetilde{x}_{13} & \ldots & \widetilde{x}_{1 n} \\
\widetilde{x}_{21} & \widetilde{x}_{22} & \widetilde{x}_{23} & \ldots & \widetilde{x}_{2 n} \\
\widetilde{x}_{31} & \widetilde{x}_{32} & \widetilde{x}_{33} & \ldots & \widetilde{x}_{3 n} \\
\vdots & \vdots & \vdots & \vdots & \vdots \\
\widetilde{x}_{m 1} & \widetilde{x}_{m 2} & \widetilde{x}_{m 3} & \ldots & \widetilde{x}_{m n}
\end{array}\right]
\end{aligned}
$$

Step 4: The weighted decision matrix $D^{*}$ that is seen in equation 8 is obtained by multiplying the normalized decision matrix and criteria importance weights. The importance weights of the criteria are obtained with SWARA for this application. Table 5 shows the weighted decision matrix.

\begin{tabular}{|c|c|c|c|c|c|c|c|c|c|c|c|c|c|c|c|}
\hline Criteria & $\mathrm{C}_{1}$ & $\mathrm{C}_{2}$ & $\mathrm{C}_{3}$ & $\mathrm{C}_{4}$ & $C_{5}$ & $\mathrm{C}_{6}$ & $\mathrm{C}_{7}$ & $\mathrm{C}_{8}$ & $\mathrm{C}_{9}$ & $C_{10}$ & $C_{11}$ & $\mathrm{C}_{12}$ & $\mathrm{C}_{13}$ & $\mathrm{C}_{14}$ & $\mathrm{C}_{15}$ \\
\hline $\operatorname{Min} / \max$ & $\min$ & $\min$ & $\min$ & $\max$ & $\max$ & $\max$ & $\max$ & $\max$ & $\max$ & $\max$ & $\max$ & $\max$ & $\max$ & $\min$ & $\min$ \\
\hline Weights & 0.091 & 0.089 & 0.090 & 0.072 & 0.076 & 0.067 & 0.047 & 0.066 & 0.095 & 0.059 & 0.050 & 0.055 & 0.058 & 0.041 & 0.043 \\
\hline $\mathrm{A}_{1}$ & 4000 & 3000 & 65 & 95 & 1000 & 40 & 100 & 70 & 40 & 40 & 40 & 35 & 40 & 50 & 50 \\
\hline $\mathrm{A}_{2}$ & 7000 & 7000 & 100 & 90 & 950 & 80 & 100 & 80 & 80 & 100 & 80 & 80 & 80 & 45 & 20 \\
\hline $\mathrm{A}_{3}$ & 6000 & 6000 & 80 & 100 & 1050 & 100 & 85 & 100 & 100 & 80 & 100 & 100 & 100 & 60 & 80 \\
\hline $\mathrm{A}_{4}$ & 5000 & 4000 & 40 & 100 & 1000 & 65 & 50 & 95 & 70 & 45 & 65 & 60 & 70 & 40 & 100 \\
\hline
\end{tabular}

$$
\begin{gathered}
C_{1} \\
D^{*}= \\
A_{1} \\
A_{2} \\
A_{3} \\
\vdots \\
A_{m}
\end{gathered}\left[\begin{array}{cccccc}
d_{11} & d_{12} & d_{13} & \ldots & \multicolumn{2}{c}{C_{n}} \\
d_{21} & d_{22} & d_{23} & \ldots & d_{1 n} \\
d_{31} & d_{32} & d_{33} & \ldots & d_{3 n} \\
\vdots & \vdots & \vdots & \vdots & \vdots \\
d_{m 1} & d_{m 2} & d_{m 3} & \cdots & d_{m n}
\end{array}\right]
$$

Step 5: With equation 9, criteria are defined as useful ( $\max$ ) and useless ( $\mathrm{min}$ ). Useful criteria are placed in front of the matrix. Table 6 shows this matrix.

$$
\begin{aligned}
& \begin{array}{llllllllll}
C_{\max 1} & C_{\max 2} & \ldots & C_{\operatorname{maxk}} & \ldots & C_{\min (k+1)} & \ldots & C_{\operatorname{minn}}
\end{array}
\end{aligned}
$$

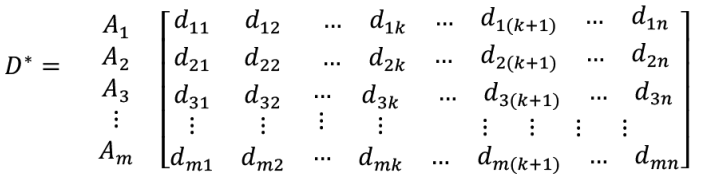

Table 4. Evaluating alternatives 
Table 5. Weighted decision matrix

\begin{tabular}{|c|c|c|c|c|c|c|c|c|c|c|c|c|c|c|c|}
\hline Criteria & $\mathrm{C}_{1}$ & $\mathrm{C}_{2}$ & $\mathrm{C}_{3}$ & $\mathrm{C}_{4}$ & $\mathrm{C}_{5}$ & $\mathrm{C}_{6}$ & $\mathrm{C}_{7}$ & $\mathrm{C}_{8}$ & $\mathrm{C}_{9}$ & $\mathrm{C}_{10}$ & $\mathrm{C}_{11}$ & $\mathrm{C}_{12}$ & $\mathrm{C}_{13}$ & $\mathrm{C}_{14}$ & $\mathrm{C}_{15}$ \\
\hline $\operatorname{Min} / \max$ & $\min$ & $\min$ & $\min$ & $\max$ & $\max$ & $\max$ & $\max$ & $\max$ & $\max$ & $\max$ & $\max$ & $\max$ & $\max$ & $\min$ & $\min$ \\
\hline $\mathrm{A}_{1}$ & 0.017 & 0.013 & 0.021 & 0.018 & 0.019 & 0.009 & 0.014 & 0.013 & 0.013 & 0.009 & 0.007 & 0.007 & 0.008 & 0.011 & 0.009 \\
\hline $\mathrm{A}_{2}$ & 0.029 & 0.031 & 0.032 & 0.017 & 0.018 & 0.019 & 0.014 & 0.015 & 0.026 & 0.022 & 0.014 & 0.016 & 0.016 & 0.009 & 0.003 \\
\hline $\mathrm{A}_{3}$ & 0.025 & 0.027 & 0.025 & 0.019 & 0.020 & 0.024 & 0.012 & 0.019 & 0.033 & 0.018 & 0.018 & 0.020 & 0.020 & 0.013 & 0.014 \\
\hline $\mathrm{A}_{4}$ & 0.021 & 0.018 & 0.013 & 0.019 & 0.019 & 0.015 & 0.007 & 0.018 & 0.023 & 0.010 & 0.011 & 0.012 & 0.014 & 0.008 & 0.017 \\
\hline
\end{tabular}

Table 6. Replacing of useful and useless criteria

\begin{tabular}{|c|c|c|c|c|c|c|c|c|c|c|c|c|c|c|c|}
\hline \multirow{2}{*}{ Criteria } & \multicolumn{10}{|c|}{ Useful criteria } & \multicolumn{5}{|c|}{ Useless criteria } \\
\hline & $\mathrm{C}_{4}$ & $\mathrm{C}_{5}$ & $\mathrm{C}_{6}$ & $\mathrm{C}_{7}$ & $\mathrm{C}_{8}$ & $\mathrm{C}_{9}$ & $\mathrm{C}_{10}$ & $\mathrm{C}_{11}$ & $C_{12}$ & $\mathrm{C}_{13}$ & $\mathrm{C}_{1}$ & $\mathrm{C}_{2}$ & $\mathrm{C}_{3}$ & $\mathrm{C}_{14}$ & $C_{15}$ \\
\hline $\operatorname{Min} / \max$ & $\max$ & $\max$ & $\max$ & $\max$ & $\max$ & $\max$ & $\max$ & $\max$ & $\max$ & $\max$ & $\min$ & $\min$ & $\min$ & $\min$ & $\min$ \\
\hline $\mathrm{A}_{2}$ & 0.017 & 0.018 & 0.019 & 0.014 & 0.015 & 0.026 & 0.022 & 0.014 & 0.016 & 0.016 & 0.029 & 0.031 & 0.032 & 0.009 & 0.003 \\
\hline $\mathrm{A}_{3}$ & 0.019 & 0.020 & 0.024 & 0.012 & 0.019 & 0.033 & 0.018 & 0.018 & 0.020 & 0.020 & 0.025 & 0.027 & 0.032 & 0.013 & 0.014 \\
\hline
\end{tabular}

Step 6: With the help of equation 10 and equation $11, S_{i+}$ and $S_{i-}$ values are obtained respectively for useful and useless criteria and the results are shown in Table 7.

$$
\begin{aligned}
& S_{i+}=\sum_{j=1}^{k} d_{i j}, j=1,2, \ldots, k \\
& S_{i-}=\sum_{j=(k+1)}^{n} d_{i j}, j=k+1, k+2, \ldots, n
\end{aligned}
$$

Step 7: With equation 12, the relative importance weight $Q_{i}$ is obtained for each alternative and shown in Table 7.

$$
Q_{i}=S_{i+} \oplus \frac{\sum_{i=1}^{m} S_{i-}}{S_{i-} \otimes \sum_{i=1}^{m} \frac{1}{S_{i-}}}
$$

Step 8: The alternative with the highest $Q_{i}$ is chosen as the best (equation 13 is below).

$$
Q_{\max }=\max _{i}\left\{Q_{i}\right\} i=1,2, \ldots, m
$$

According to Table 7, the " $A_{3}$ - Turquoise" is the best shipyard alternative with a value of 0.282 .

Table 7. $Q_{i}$ values

\begin{tabular}{|c|c|c|c|c|}
\hline & $\boldsymbol{A}_{\boldsymbol{1}}$ & $\boldsymbol{A}_{\mathbf{2}}$ & $\boldsymbol{A}_{\mathbf{3}}$ & $\boldsymbol{A}_{\mathbf{4}}$ \\
\hline$S_{i+}$ & 0.122 & 0.184 & 0.209 & 0.154 \\
\hline$S_{i \cdot}$ & 0.069 & 0.104 & 0.102 & 0.075 \\
\hline$Q_{i}$ & 0.230 & 0.256 & 0.282 & 0.253 \\
\hline
\end{tabular}

Step 9: Using equation 14, the performance index of all alternatives $P_{i}$ is obtained. For the best alternative, $P_{\text {best }}=100$. Table 8 shows the $P_{i}$ values and ranking of alternatives.

$P_{i}=\frac{Q_{i}}{Q_{\max }} \otimes 100 \%$

According to the research model, the " $A_{3}$ - Turquoise" was found to be the most suitable shipyard for the 30-meter motor yacht construction in Turkey by its performance index value, which is 100.00. The " $A_{2}$ - Sarp Shipyard" was the second best shipyard with a performance index value of 90.61 and the last shipyard was the " $A_{1}$ - Ada Shipyard" with a performance index value of 81.51 . According to the results given in Table 8 , the ranking of the shipyards in which a 30-meter motor yacht can be constructed according to the proposed research model in this paper is İstanbul, Antalya, Tuzla, and Muğla.

\section{Conclusion}

The yacht and boat industry is different from the shipbuilding industry with its content, terminology, investment, operation, and technology in Turkey, same as with all over the world. The only common aspect of the shipbuilding industry and the yacht building industry is

Table 8. $P_{i}$ values and ranking of alternatives

\begin{tabular}{|c|c|c|c|c|}
\hline & $\begin{array}{c}A_{1}-\text { Muğla } \\
\text { Ada Ship- } \\
\text { yard }\end{array}$ & $\begin{array}{c}A_{2}-\text { Antalya } \\
\text { Sarp Ship- } \\
\text { yard }\end{array}$ & $\begin{array}{c}A_{3}-\text { İstan- } \\
\text { bul } \\
\text { Turquoise }\end{array}$ & $\begin{array}{c}A_{4}-\text { Tu- } \\
\text { zla } \\
\text { ICT }\end{array}$ \\
\hline$P_{i}$ & 81.51 & 90.61 & 100.00 & 89.55 \\
\hline Ranking & 4 & 2 & 1 & 3 \\
\hline
\end{tabular}


that their products swim in the sea. While the shipbuilding industry needs large investments, long periods of time, and large areas near the sea, the yacht and boat manufacturing industry can be managed without much need for smaller investments, shorter times, smaller places, and the seaside.

Compared to the length of the coast with the number of boats per capita, Turkey has great potential in the boat and yacht industry.

In this point, a sequential solution methodology that consists of the SWARA and COPRAS was proposed for choosing the most suitable shipyard in constructing a new motor yacht, and alternatives were evaluated by determining the weights of the criteria determined within the proposed model. For solving the most suitable shipyard to the 30 -meter motoryacht construction problem in Turkey, four alternatives with different characteristics in different cities of the country were evaluated. As a result of the proposed method, the Turquoise Yachting from İstanbul was found to be the most appropriate shipyard.

Although this paper can contribute to the literature and guide to future studies, the most important limitation of this study is the subjective criteria used in the scope of the study. Even though attempts were made to minimize the number of subjective criteria in the study, only 3 out of 15 criteria were evaluated with definite numbers. At this point, besides the knowledge and experience of decision makers, it is also not possible to predict the instinct factor that will be effective in their decision-making process. Another limitation of the study the avoidance of computational complexity. According to the experts' opinion, only four shipyards were selected and evaluated among all shipyards located in Turkey. In the future, it is possible to eliminate this limitation with the evaluation of all shipyards located in Turkey for motor-yacht construction. In addition, it will be possible to evaluate all shipyards in the direction of the needs of the manufacturing companies that want to produce a similar production worldwide with the proposed research model.

As a result, when developed countries are examined, it can be seen that these countries are going forward in the maritime industry. Moreover, their economies have made the greatest contribution from the maritime industry and they have adopted the maritime industry as a culture. With this understanding, it should not be forgotten that the number of amateur seafarers in developed countries is high and that amateur maritime cultures have been adopted by society since childhood. The dissemination of this culture in Turkey is quite important for the development of the maritime sector. The most basic starting point for the development of the maritime economy of Turkey with maximum benefit will be the adoption of the maritime culture.
Funding: The author declared that this study received no financial support.

\section{References}

[1] West Mediterranean Development Agency, "Yatçllık sektör raporu," 2012, [Online]. Available: https://baka.gov.tr/ uploads/1357649647YATCiLiK-SEKTORU-RAPORU-5ARALIK. pdf. [Accessed: Jul. 31, 2021]

[2] Turkish Chamber of Commerce, "Rakamlarla denizcilik sektörü ve istatistikler," 2017. IMEAK. [Online] Available: https:// www.denizticaretodasi.org.tr/Media/SharedDocuments / DenizTicaretiDergisi/mart_ek_2017.pdf. [Accessed: Jul. 28, 2021].

[3] P. Rani, A.R. Mishra, A. Mardani, F. Cavallaro, D. Streimikiene and S.A.R. Khan, "Pythagorean fuzzy SWARA-VIKOR framework for performance evaluation of solar panel Selection." Sustainability, vol. 12, pp. 1-18, May 2020.

[4] A. Mostafaeipour, S.J.H. Dehshiri and S.S.H. Dehshiri, "Ranking locations for producing hydrogen using geothermal energy in Afghanistan." International Journal of Hydrogen Energy, vol. 45, pp. 15924-15940, Jun 2020.

[5] A. Mardani, M.K. Saraji, A.R. Mishra and P. Rani, "A novel extended approach under hesitant fuzzy sets to design a framework for assessing the key challenges of digital health interventions adoption during the COVID-19 outbreak." Applied Soft Computing, vol. 96, pp. 106613, Nov 2020.

[6] W. Chen, X. Chen, J. Peng, M. Panahi and S. Lee, "Landslide susceptibility modeling based on ANFIS with teaching-learningbased optimization and Satin bowerbird optimizer." Geoscience Frontiers, vol. 12, pp. 93-107, Jan 2021.

[7] M.A. Naeini, M. Zandieh, S. E. Najafi, and S.M. Sajadi, "Analyzing the development of the third-generation biodiesel production from microalgae by a novel hybrid decision-making method: The case of Iran." Energy, vol. 195, pp. 116895, Mar 2020.

[8] S. Mousavi-Nasab and A. Sotoudeh-Anvari, "An extension of best-worst method with D numbers: application in evaluation of renewable energy resources." Sustainable Energy Technologies and Assessments, vol. 40, pp. 100771, Aug 2020.

[9] A. Balali, A. Hakimelahi and A. Valipour, "Identification and prioritization of passive energy consumption optimization measures in the building industry: An Iranian case study." Journal of Building Engineering, vol. 30, pp. 101239, Jul 2020.

[10] A. Roozbahani, H. Ghased and M.H. Shahedany, "Inter-basin water transfer planning with grey COPRAS and fuzzy COPRAS techniques: a case study in Iranian Central Plateau." Science of The Total Environment, vol. 726, pp. 138499, Jul 2020.

[11] H.S. Dhiman and D. Deb, "Fuzzy TOPSIS and fuzzy COPRAS based multi-criteria decision making for hybrid wind farms." Energy, vol. 202, pp. 117755, Jul 2020.

[12] P. Rani, A.R. Mishra, and A. Mardani, "An extended Pythagorean fuzzy complex proportional assessment approach with new entropy and score function: application in pharmacological therapy selection for type 2 diabetes." Applied Soft Computing, vol. 94, pp. 106441, Sep 2020.

[13] P.S. Kathamore and B.D. Bachchhav, "Grade classification of biobased lube oil by multi attribute decision making methods." Materialstoday: Proceedings, vol. 43, pp. 760-768, Jul 2020. 
[14] A.R. Mishra, P. Rani, A. Mardani, K.R. Pardasani, K. Govindan and M. Alrasheedi, "Healthcare evaluation in hazardous waste recycling using novel interval-valued intuitionistic fuzzy information based on complex proportional assessment method." Computers \& Industrial Engineering, vol. 139, pp. 106140, Jan 2020.

[15] R. Kumari and A.R. Mishra, "Multi-criteria COPRAS method based on parametric measures for intuitionistic fuzzy sets: application of green supplier selection." Iranian Journal of Science and Technology, Transactions of Electrical Engineering, vol. 44, pp. 1645-1662, Jan 2020.

[16] H. Garg and R. Arora, "Algorithms based on COPRAS and aggregation operators with new information measures for possibility intuitionistic fuzzy soft decision-making." Mathematical Problems in Engineering, pp. 1563768, 2020.

[17] T. Singh, A. Patnaik, G. Fekete, R. Chauhan and B. Gangil, "Application of hybrid analytical hierarchy process and complex proportional assessment approach for optimal design of brake friction materials." Polymer Composites, vol. 40, pp. 1602-1608, 2019.

[18] N. Zarbakhshnia, H. Soleimani and H. Ghaderi, "Sustainable third-party reverse logistics provider evaluation and selection using fuzzy SWARA and developed fuzzy COPRAS in the presence of risk criteria." Applied Soft Computing, vol. 65, pp. 307-319, Apr 2018.

[19] A. Valipour, N. Yahaya, N.M.D. Noor, I. Valipour and J. Tamosaitiene, "A SWARA-COPRAS approach to the allocation of risk in water and sewerage public-private partnership projects in Malaysia." International Journal of Strategic Property Management, vol. 23, pp. 269-283, 2019.

[20] G.N. Yücenur, Ş. Çaylak, G. Gönül and M. Postalcıŏlu, "An integrated solution with SWARA\&COPRAS methods in renewable energy production: city selection for biogas facility." Renewable Energy, vol. 145, pp. 2587-2597, Jan 2020.

[21] Z.N. Ansari, R. Kant, and R. Shankar, "Evaluation and ranking of solutions to mitigate sustainable remanufacturing supply chain risks: a hybrid fuzzy SWARA-fuzzy COPRAS framework approach." International Journal of Sustainable Engineering, vol. 13, pp. 473-94, May 2020.

[22] A.R. Mishra, et al. "Novel multi-criteria intuitionistic fuzzy SWARA-COPRAS approach for sustainability evaluation of the bioenergy production process." Sustainability, vol. 12, pp. 4155 , May 2020.

[23] P. Rani, et al. "Hesitant fuzzy swara-complex proportional assessment approach for sustainable supplier selection (HFSWARA-COPRAS)." Symmetry, vol. 12, pp. 1152, Jul 2020.

[24] Republic of Turkey Ministry of Commerce, "General Directorate of Export," [Online]. Available: https:// ticaret.gov.tr/data / 5 b8 7000813 b8761450e18d7b/ Gemi_\%C4\%B0n\%C5\%9Fa_\%20Sanayii.pdf. [Accessed: Jul. 30, 2021]

[25] V. Keršuliene, E.K. Zavadskas, and Z. Turskis, "Selection of rational dispute resolution method by applying new step-wise weight assessment ratio analysis (SWARA)." Journal of Business Economics and Management, vol. 11, pp. 243-258, Mar 2010.

[26] V. Keršuliene and Z. Turskis, "Integrated fuzzy multiple criteria decision making model for architect selection." Technological and Economic Development of Economy, vol. 17, pp. 645-666, Oct 2011.

[27] E. K. Zavadskas, A. Kaklauskas and T. Vilutiene T, "Multicriteria evaluation of apartment blocks maintenance contractors: Lithuanian case study." International Journal of Strategic Property Management, vol. 13. pp. 319-338, Sep 2009. 